\title{
The Effects of Firing Temperatures on the Performance of Insulating Firebricks Containing Different Proportions of Alumina and Sawdust
}

\author{
Davies Oladayo Folorunso ${ }^{1,2^{*}}$, Fatai Olufemi Aramide' ${ }^{1,2}$, Peter Olubambi ${ }^{1,2,3}$, \\ Joseph Olatunde Borode ${ }^{1,2}$ \\ ${ }^{1}$ Department of Metallurgical and Materials Engineering, Federal University of Technology, Akure, Nigeria \\ ${ }^{2}$ Africa Materials Science And Engineering Networks: A Carnegie-IAS (RISE) Networks (FUTA Node), Akure, Nigeria \\ ${ }^{3}$ Department of Chemical and Metallurgical Engineering, Tshwane University of Technology, Pretoria, \\ South Africa \\ Email: dofolorunso@futa.edu.ng
}

Received 13 May 2015; accepted 21 June 2015; published 24 June 2015

Copyright (C) 2015 by authors and Scientific Research Publishing Inc.

This work is licensed under the Creative Commons Attribution International License (CC BY). http://creativecommons.org/licenses/by/4.0/

\section{Open Access}

\section{Abstract}

This work studied the effects of firing temperatures on the refractory properties of insulating firebricks produced from a blend of hydrometallurgically purified clay, high alumina cement and sawdust. Twenty grams out of a bulk $(1000 \mathrm{Kg})$ of clay obtained from Ipetumodu in Nigeria was analyzed for size range, consequent upon which the remaining bulk was sieved to $100 \mu \mathrm{m}$, being the average size. The bulk was there after leached under a predetermined condition $\left(1.6 \mathrm{~mol} / \mathrm{dm}^{3}\right.$ of oxalic acid at $70^{\circ} \mathrm{C}$ for $150 \mathrm{~min}$ and $200 \mathrm{rev} / \mathrm{min}$ agitation speed) and cylindrical samples (5 cm diameter by $5 \mathrm{~cm}$ high) containing different quantities of high alumina cement (5\%-20\%) and sawdust (1\% - 5\%) were prepared, dried at $110^{\circ} \mathrm{C}$ and subsequently fired at $900^{\circ} \mathrm{C}, 1100^{\circ} \mathrm{C}, 1300^{\circ} \mathrm{C}$ and $1500^{\circ} \mathrm{C}$, at the rate of $4^{\circ} \mathrm{C} / \mathrm{min}$ and soaked for $2 \mathrm{hrs}$. These samples were subjected to different refractory tests (permanent linear change, modulus of rupture, bulk density, cold crushing strength and apparent porosity). Even though samples containing more than $20 \%$ alumina crumbled at elevated temperatures, it was still observed that the bricks performed to expectations at lower alumina contents, even at $1500^{\circ} \mathrm{C}$. The sample containing $3 \%$ sawdust and $10 \%$ alumina cement however, gave the desired requirement for preparing good insulating firebricks with reliable phase integrity, as revealed by scanning electron microscopy (SEM).

\section{Keywords}

Firing Temperature, Hydrometallurgy, Insulating Firebrick, Phase Integrity, Sawdust,

"Corresponding author. 


\section{High Alumina Cement}

\section{Introduction}

Insulating fire bricks, though specially designed for high heat environment, will eventually start to fail and break down over time. This necessitates a periodical replacement of the firebricks with new ones in order to ensure that the bricks work as intended, which in turn accounts, therefore, for the regular demands for firebricks by the industries and outfits where the bricks are used [1].

Firebrick is a generic name that encompasses any brick that can withstand repeated heating and cooling at various temperature ranges. Additionally, firebricks must be able to withstand different atmospheres, provide various structural or insulating qualities, and due to the difficulty in cutting them, must be available in a variety of shapes to add flexibility to kiln design and construction.

Composite refractory brick has been identified as a solution to obtain both chemical and physical properties needed to be possessed by a good refractory brick. This is achieved by a blend of clay with either synthetic or organic additives [2].

Conditions that refractories must withstand vary a great deal from one application to another. One especially difficult condition occurs during the firing of glazed ceramics, when some of the alkali vaporizes at firing temperatures. These vapors react with some refractory products and result in high reject rates.

This research was prompted by the need to improve the refractoriness of clay, which is the major component of the insulating firebrick. This was accomplished by processing the clay hydrometallurgically in order to remove the iron content, iron being responsible for lowering the refractoriness of clay. The usefulness of sawdust, which hitherto, was regarded as a waste was also exploited.

\section{Materials and Methods}

The materials and equipment used were raw Ipetumodu clay, oxalic acid (99.8\% purity), alumina cement (Secar 71), X-ray diffraction (XRD) machine (model Philips PW 3710 with PW 1752 graphite monocromator), X-ray fluorescence (XRF) machine (model ARL 8410), scanning electron microscope (SEM) model JEOL 840 and coupled with an EDS analyzer,atomic absorption spectrometer (AAS) machine (model Spectre AA 220 FS), sieve size analyser (Microtrac FLEX 10.5.4), Labcon shaking incubator (models 3081U and 5082U), Carbolite furnace, Rawwley Sussex jaw crusher and grinder and Compression testing machine (model Pat. 2001).

\subsection{Raw Clay Preparation for Analysis}

A good quantity of potter's clay was mined from Ipetumodu in Osun State, Nigeria. It was then washed in water in order to remove the deleterious particles by decantation. Water was then drained from the clay slurry using a plaster of Paris (P.O.P.) mould. The recovered clay was then dried in the sun for three days and again in the Carbolite furnace at $90^{\circ} \mathrm{C}$ for 8 hours. The dried clay was finally jaw crushed and ground in a Rawwley Sussex grinder to finer size.

\subsection{Particle Size Analysis}

Size analysis was carried out on the ground clay using Microtrac FLEX 10.5.4 Filter enabled analyzer. $20 \mathrm{~g}$ of the clay was fed into the machine, with a loading factor of 0.0173 , transmission rate of 0.851 and allowed to run for 10 seconds. The average sieve size was found to be about $100 \mu \mathrm{m}$. The result is as presented in Figure 1. The bulk of the clay was therefore sieved to $100 \mu \mathrm{m}$ for subsequent analyses carried out on it, in order to ensure uniformity.

\subsection{Characterization of Clay}

Analyses of the clay were carried out using SEM/EDS, XRD and XRF according to the standard procedure [3]. The results are presented in Figure 2, Figure 3 and Table 1 respectively.

\subsection{Hydrometallurgical Purification of Clay}

The clay was purified hydrometallurgically, using $1.6 \mathrm{~mol} / \mathrm{dm}^{3}$ of oxalic acid at $70^{\circ} \mathrm{C}$ for $150 \mathrm{~min}$. and $200 \mathrm{rev} /$ 
min agitation speed [4]. A substantial quantity of clay and 5 times by volume of $1.6 \mathrm{~mol} / \mathrm{dm}^{3}$ of prepared oxalic acid solution were introduced into a flat-bottom glass bowl and put inside the Labcon shaking incubator, models

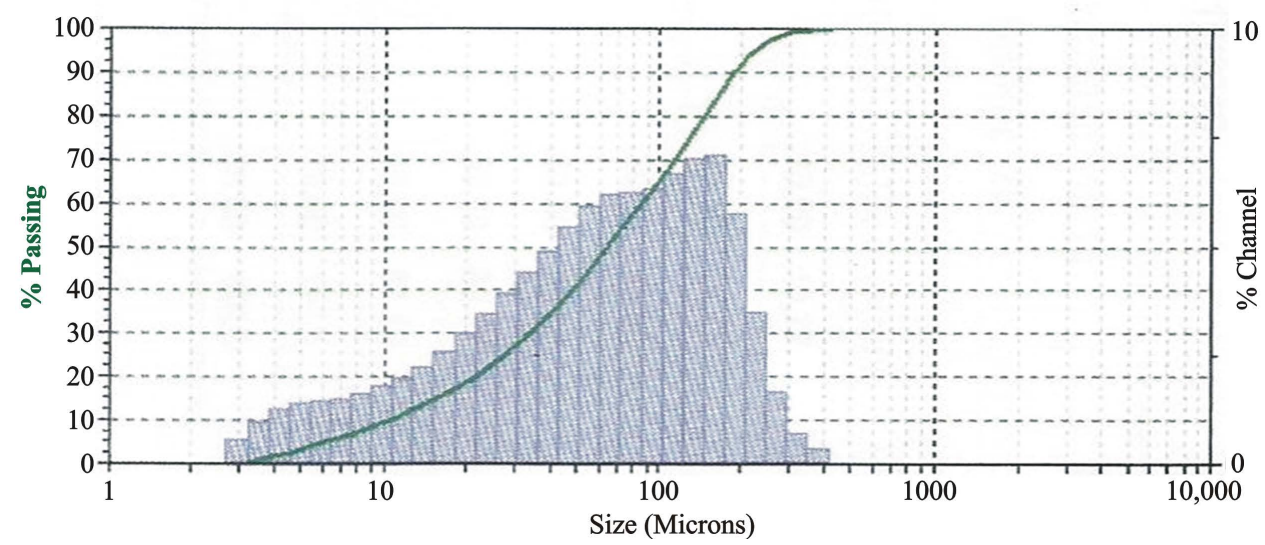

Figure 1. Sieve analysis of Ipetumodu clay.
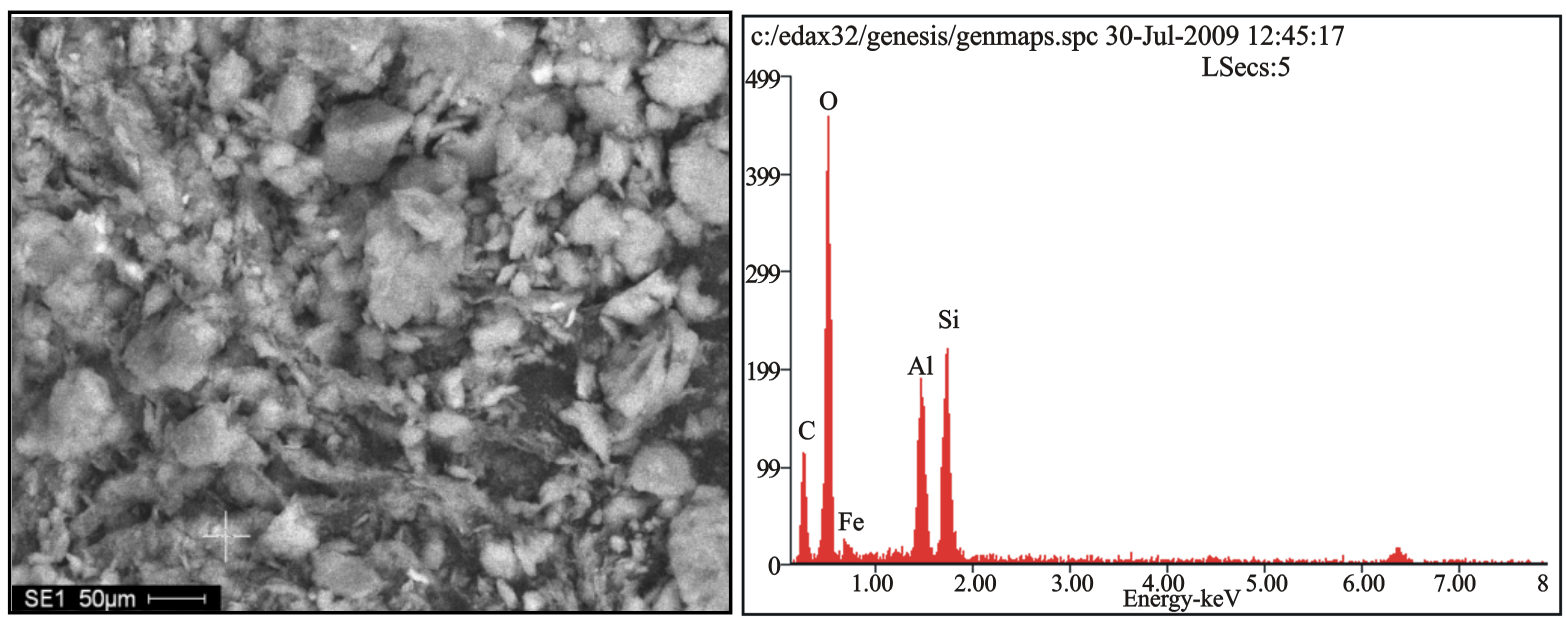

Figure 2. SEM micrograph (X500) and EDS pattern for raw Ipetumodu clay sample.

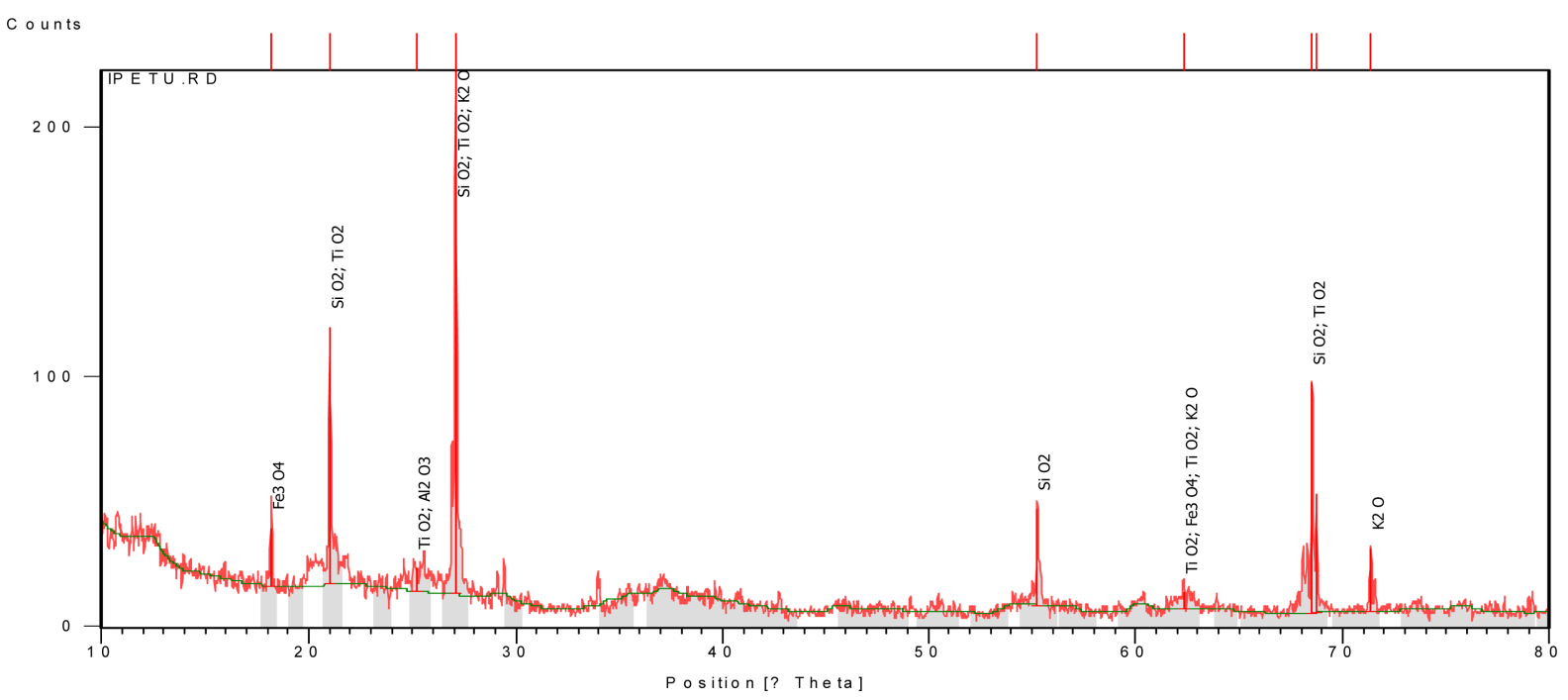

Figure 3. X-ray diffraction pattern for raw Ipetumodu clay. 
$3081 \mathrm{U}$ and $5082 \mathrm{U}$ for agitation at $70^{\circ} \mathrm{C}$ for $150 \mathrm{~min}$. On the expiration of the set time, the bowl was removed and allowed to cool to room temperature. The filtrate was decanted and the residue washed several times with deionized water, until all the acid content was completely removed. This was ensured by testing intermittently with a blue litmus paper, until no further change in colour was observed. The clay residue was then dried in the Carbolite furnace at $90^{\circ} \mathrm{C}$, crushed, ground and sieved to $100 \mu \mathrm{m}$ for subsequent tests.

\subsection{Samples Preparation for Refractory Tests}

Measures (150 g each) of the purified clay with varying quantities $(5 \%, 10 \%, 15 \%, 20 \%, 25 \%, 30 \%, 35 \%$ and $40 \%$ ) of highalumina cement (Secar 71) and $1 \%-5 \%$ of saw dust was formed into cylindrical (50 mm diameter $\times 50 \mathrm{~mm}$ high)specimens after mixing with about $(10-15) \%$ deionized water. The samples were dried in airfor $24 \mathrm{hrs}$ and later in the oven at $110^{\circ} \mathrm{C}$ for $48 \mathrm{hrs}$. Some selected samples, after drying at $110^{\circ} \mathrm{C}$ were again taken for firing in the furnace at $900^{\circ} \mathrm{C}, 1100^{\circ} \mathrm{C}, 1300^{\circ} \mathrm{C}$ and $1500^{\circ} \mathrm{C}$. The fired samples were subsequently tested inaccordance with the American Standard for Testing and Materials (ASTM) for the following properties:

\subsubsection{Permanent Linear Change}

Permanent linear change tests were carried out in accordance with the [5] standard. The heights of the firebrick test samples were measured with vernier callipers before firing at various temperatures. Three different linear measurements were taken in each case and the average calculated. The test samples were then fired at temperatures of $900^{\circ} \mathrm{C}, 1100^{\circ} \mathrm{C}, 1300^{\circ} \mathrm{C}$ and $1500^{\circ} \mathrm{C}$ for 2 hours at the rate of $4^{\circ} \mathrm{C}$ per min, after which they were slowly cooled to the room temperature. The heights of the fired test specimens were again measured in order to determine the changes in heights. The results are as presented in Figure 4.

\subsubsection{Bulk Densities and Cold crushing strengths}

Test specimens fired at varying temperatures of $900^{\circ} \mathrm{C}, 1100^{\circ} \mathrm{C}, 1300^{\circ} \mathrm{C}$ and $1500^{\circ} \mathrm{C}$ were produced. The masses, heights and diameters of the specimens were measured. The bulk densities of these specimens were computed and results presented in Figure 5. To determine the cold crushing strength, the specimens were subjected to compressive load until fracture, using an Auto Compression Testing Machine model Pat 2001. The results are presented in Figure 6.

\subsubsection{Modulus of Rupture (MOR)}

According to [6], modulus of rupture is defined as the maximum stress a rectangular test piece $(150 \mathrm{~mm} \times 25$ $\mathrm{mm} \times 25 \mathrm{~mm}$ ) can withstand in a 3-point bending test until it breaks. In doing this, test specimens were prepared, dried at $110^{\circ} \mathrm{C}$, allowed to cool to the room temperature and fired to $1500^{\circ} \mathrm{C}$. Some of the samples were tested after cooling from $1500^{\circ} \mathrm{C}$ to the room temperature and the others were tested while the samples were right inside the MOR furnace at $1500^{\circ} \mathrm{C}$. In each case, three samples were tested and the average values taken. The results are as presented in Figure 7.

\subsubsection{Apparent Porosity}

The apparent porosities of the samples were measured to standard [7], using test specimens which had been dried in an oven at $110^{\circ} \mathrm{C}$ to a constant weight within $0.1 \mathrm{~g}$ accuracy and cooled to room temperature. This test was carried out for specimens without and with 1\% - 5\% sawdust. The results are presented in Figure 8 and Figure 9 respectively. From these and according to the ASTM standard, the percentage of sawdust required to produce firebricks of the stipulated $45 \%-70 \%$ porosity, recommended for good insulating firebricks, was determined.

\section{Results and Discussion}

\subsection{Sieve Analysis}

The sieve analysis shows an average sieve size of about $100 \mu \mathrm{m}$. This accounted for sieving the bulk of the clay to $100 \mu \mathrm{m}$, in order to ensure uniformity throughout the course of the research.

\subsection{Scanning Electron Microscopy (SEM)}

The SEM/EDS analysis shows the SEM micrographs of the relative sizes of the clay particles at X500 magnifi- 
cation and the spectra depicting the peaks of the elements present. The EDS shows the actual percentages of the various elements contained in the clay. The clay contained some quantity of iron, principally in the iron oxide mineral. Thisand other minerals contained in the clay were quantified in the XRF analysis in Table 1.

\subsection{X-Ray Diffraction (XRD)}

The qualitative analysis of the clay as depicted by the XRD pattern shows sharp high peaks for $\mathrm{SiO}_{2}, \mathrm{Al}_{2} \mathrm{O}_{3}$, $\mathrm{Fe}_{3} \mathrm{O}_{4}$ and sharp but shorter peaks for $\mathrm{K}_{2} \mathrm{O}, \mathrm{MgO}, \mathrm{MnO}, \mathrm{Na}_{2} \mathrm{O}$ and $\mathrm{CaO}$. Some other oxides were also present but in very negligible proportions.

\subsection{XRF of the Raw and Leached Clay Samples}

The results of the chemical analyses by X-ray Fluorescence are presented in Table 1 . The Table shows semiquantitative analysis of the clay, revealing the percentages of the principal minerals and elements present.

The Major minerals contained in the clay are $\mathrm{SiO}_{2}$ and $\mathrm{Al}_{2} \mathrm{O}_{3}$, which constituted more than $80 \%$. The other mineral present in some appreciable quantity was $\mathrm{Fe}_{2} \mathrm{O}_{3}(6.94 \%)$. Present in very small quantities were $\mathrm{K}_{2} \mathrm{O}$, $\mathrm{MgO}, \mathrm{CaO}, \mathrm{Na}_{2} \mathrm{O}$ and $\mathrm{MnO}$ minerals. The remaining minerals exist in negligible quantities of less than $1 \%$. Their presence has been found not to constitute any threats to the expected performance of the firebrick at high temperatures [4] [8].

It is expected that most of the major minerals will enhance the desirable properties. However, the presence of iron oxide $\left(\mathrm{Fe}_{2} \mathrm{O}_{3}\right)$ is detrimental and must be reduced to an acceptable level of less than 1\% [9]. Therefore, forthe clay to perform satisfactorily as insulating firebricks, the iron oxide level was reduced by hydrometallurgical purification. Purification was further necessitated by the need to justify the following facts as established by $[10]$.

1) Percentage sum total of $\mathrm{K}_{2} \mathrm{O}, \mathrm{Na}_{2} \mathrm{O}$ and $\mathrm{MgO}$ was more than the required standard of $2 \%$ [10]. Purification now reduced it from $4.37 \%$ to $1.83 \%$;

2) $\mathrm{CaO}$ content was less than $15 \%$ required for good refractory performance [10]. Purification now increased it from $0.36 \%$ to $8.83 \%$;

3) Silica $\left(\mathrm{SiO}_{2}\right)$ content was higher than about $50 \%$ [10]. It now reduced from $62.34 \%$ to $53.84 \%$ after purification;

4) Alumina $\left(\mathrm{Al}_{2} \mathrm{O}_{3}\right)$ content was lower than about $30 \%$ required of good insulating firebricks [10]. It has now increased from 18.48 to 23.89 .

\subsection{Quantitative Analysis of Raw and Processed Clays}

Table 2 shows the mineralogical analysis carried out to identify and determine the relative amounts of minerals contained in the clay before and after purification. The types and quantities of minerals present in any material influence its refractory performance. For refractory materials, the presence of fusible silica (quartz) or microcline is not desirable because they reduce the refractoriness. The most preferred minerals are kaolinites and muscovites/illites [4] [10]. The percentages of these preferred minerals increased appreciably while the percentages of the undesirable minerals also reduced significantly after purification.

\subsection{Permanent Linear Change (PLC)}

The results of the variation of permanent linear changes with alumina contents and firing temperatures are shown in Figure 4. It was observed that firebricks produced from the processed clay underwent linear contractions for firing temperatures of $900^{\circ} \mathrm{C}, 1100^{\circ} \mathrm{C}$ and $1300^{\circ} \mathrm{C}$ for low additions of alumina. For alumina contents between $20 \%$ and $30 \%$ the firebricks suffered permanent linear expansion after which the bricks suffered permanent linear contraction again. This is indicative of variations in the clay-alumina reactions at different alumina contents. Firing at $1500^{\circ} \mathrm{C}$ caused the firebricks to undergo a high permanent linear expansion and hence suffered dimensional instability.

When fired at $1500^{\circ} \mathrm{C}$, the bricks suffered permanent linear expansion for alumina additions up to $20 \%$, beyond which the bricks became dimensionally unstable and crumbled under its own weight. This accounted for the reason samples with $25 \%$ alumina and above did not feature on the graph (Figure 4). This implies that the firebrick so formulated will perform satisfactorily at $1500^{\circ} \mathrm{C}$ provided the alumina content is not more than $20 \%$. 
Table 1. XRF analysis of the raw and leached clays.

\begin{tabular}{cccccc}
\hline Oxides & $\mathrm{Raw}(\mathrm{wt} \%)$ & Leached $(\mathrm{wt} \%)$ & Oxides & Raw $(w t \%)$ & Leached (wt\%) \\
\hline $\mathrm{SiO}_{2}$ & 62.34 & 53.84 & $\mathrm{MnO}$ & 0.03 & 0.03 \\
$\mathrm{Al}_{2} \mathrm{O}_{3}$ & 18.48 & 23.89 & $\mathrm{TiO}_{2}$ & 1.11 & 1.17 \\
$\mathrm{CaO}$ & 0.36 & 8.38 & $\mathrm{P}_{2} \mathrm{O}_{5}$ & 0.03 & 0.03 \\
$\mathrm{Fe}_{2} \mathrm{O}_{3}$ & 6.94 & 2.59 & $\mathrm{Cr}_{2} \mathrm{O}_{3}$ & 0.02 & 0.02 \\
$\mathrm{MgO}$ & 0.63 & 0.37 & $\mathrm{NiO}$ & 0.01 & 0.01 \\
$\mathrm{~K}_{2} \mathrm{O}$ & 2.89 & 1.27 & $\mathrm{~V}_{2} \mathrm{O}_{5}$ & 0.01 & 0.02 \\
$\mathrm{Na}_{2} \mathrm{O}$ & 0.85 & 0.19 & $\mathrm{ZrO}_{2}$ & 0.06 & 0.06 \\
$\mathrm{LOI}(\mathrm{raw})$ & 6.68 & \multicolumn{5}{c}{ LOI (leached) } \\
Total & 100.44 & Total & 8.61 \\
\hline
\end{tabular}

Table 2. XRD quantitative analysis of raw and processed clays.

\begin{tabular}{c|cc}
\hline \multirow{2}{*}{ Clay minerals } & \% weight of clay minerals before and after purification \\
\cline { 2 - 3 } & Raw & Processed \\
\hline Kaolinite & 20.02 & 38.53 \\
Muscovite/illites & 15.02 & 25.71 \\
Quartz & 23.84 & 16.74 \\
Microcline & 26.10 & 7.65 \\
Plagioclase albite & 15.02 & 11.36 \\
TOTAL & 100.00 & 99.99 \\
\hline
\end{tabular}

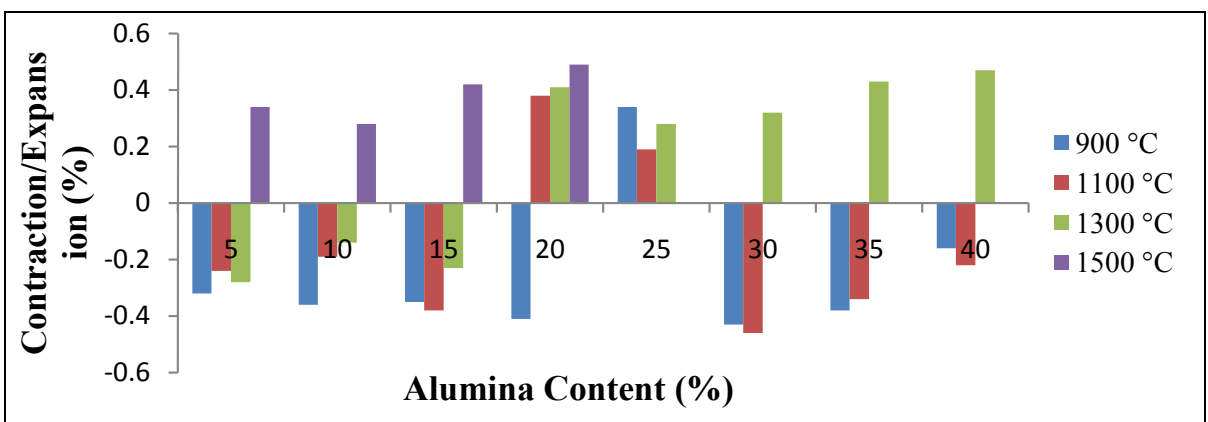

Figure 4. Permanent linear changes at different firing temperatures.

\subsection{Bulk Density}

The results of the bulk densities of firebricks when fired at different temperatures are shown in Figure 5. The results revealed that the bricks possess good bulk densities in fired conditions. As expected of any good insulating refractory, the bulk density should range between 1.6 and $2.0 \mathrm{~g} \cdot \mathrm{dm}^{-3}$ [10]. This range of values is clearly exhibited by the bricks.

Furthermore, the variation in the bulk densities was due to voids formation resulting from the burning off of sawdust, an organic matter from the bricks during firing. This organic matter was not uniformly distributed and hence the variation. However, firing at higher temperature could cause voids closure as a result of softening or liquid phase formation which could also cause bulk density variation.

\subsection{Cold Crushing Strength}

Figure 6 shows the variation of cold crushing strengths of firebricks containing 5\% to $40 \%$ alumina and fired at temperatures between $900^{\circ} \mathrm{C}$ and $1500^{\circ} \mathrm{C}$. It was observed that at all the firing temperatures, the strengths in- 
creased to the maximum at about $10 \%-15 \%$ alumina and then decreased at higher alumina content. Also, the lower the quantity of alumina, the higher the firing temperature at which the maximum strength was obtained. This trend can be attributed to the fact that the low melting compounds burn off completely at higher firing temperature thereby reducing the cohesiveness of the clay grains and consequently the adhesion of the grains to alumina as well. The reduction in the cohesive and adhesive forces leads to the reduction in the crushing strength.

The trend (reduced strength) was more evident at $1500^{\circ} \mathrm{C}$ and alumina content above $20 \%$ when the samples crumbled completely right inside the furnace because of the reduced strength. Figure 6 therefore has zero values for samples fired at $1500^{\circ} \mathrm{C}$ with alumina contents above $20 \%$. Even though the sample fired at $900^{\circ} \mathrm{C}$ exhibited a reasonably high crushing strength, the fact still remains that higher firing temperature is more desirable and, above all, the alumina content at which this occurred (25\%) was grossly uneconomical for industrial production. It therefore becomes imperative to choose $10 \%$ alumina as optimum, which is in agreement with [6].

\subsection{Modulus of Rupture (MOR)}

The modulus of rupture values at the room temperature and $1500^{\circ} \mathrm{C}$ are shown in Figure 7 . The values were very much lower when tested at $1500^{\circ} \mathrm{C}$ than at the room temperature, $30^{\circ} \mathrm{C}$. The modulus of rupture (MOR) increased progressively with the quantity of alumina in the cold state while it only increased to the maximum at $10 \%$ alumina and dropped again when tested at $1500^{\circ} \mathrm{C}$. The trend was due to the fact that the liquid so formed when the samples were first heated and allowed to cool had solidified to form glassy phase which further strengthened the samples. On the other hand, when the samples were rupture tested at the elevated temperature of $1500^{\circ} \mathrm{C}$, the samples were still in the molten state and thus the strength was comparatively lower than when it had solidified to form glassy phase.

However, the MOR attained maximum at $10 \%$ alumina because the liquid phase formed when fired was adequately matched with the alumina present to form a solid mass and hence the relatively higher strength than at $15 \%$ and $20 \%$ alumina where the liquid phase was predominant.

\subsection{Apparent Porosity (AP)}

The results of the apparent porosities of samples with 5\% - 20\% alumina are as presented in Figure 8. The apparent porosities reduced with alumina contents because the pores were reduced as a result of the binding effect of alumina which reduces the interparticle distances between the grains. The maximum porosity obtained was $30.62 \%$, which was much lower than the $45 \%$ required for insulating firebricks [6]. This accounted for the introduction of sawdust which is expected to burn off at high temperature in order to further create pores for easy passage of the evolved gases.

The apparent porosities were improved upon by the addition of sawdust in the range of $1 \%-5 \%$. The results are as presented in Figure 9. The apparent porosity increased as the percentage sawdust was increased at all levels of alumina content because the saw dust burnt off at the elevated temperature of $1500^{\circ} \mathrm{C}$. The more the sawdust added, the more the pores created. Despite this trend, the porosity still reduced with alumina at each sawdust

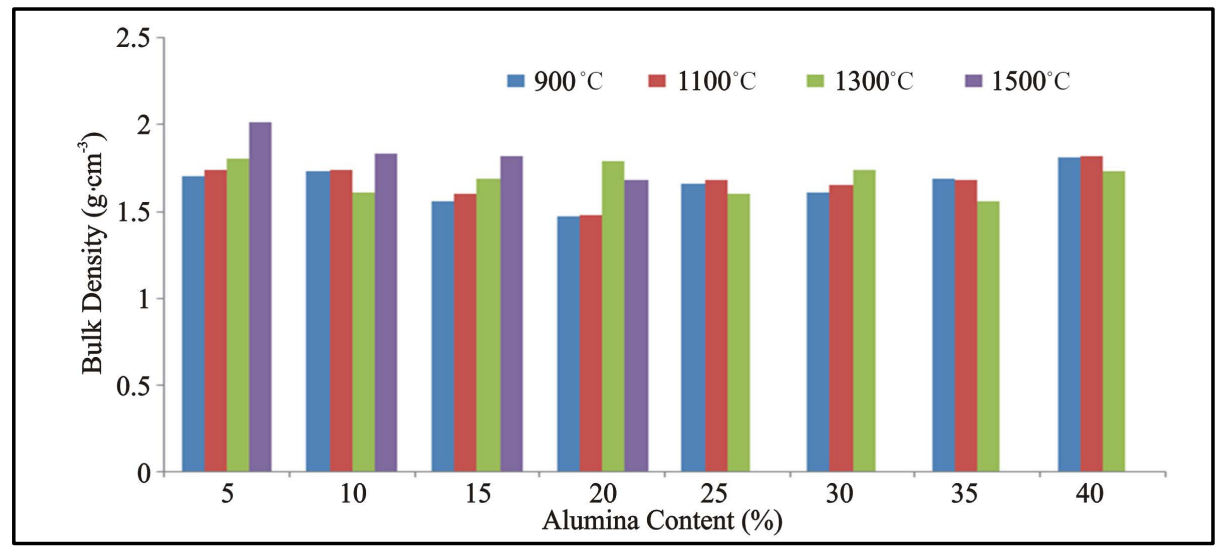

Figure 5. Bulk densities of leached clay at various firing temperatures. 


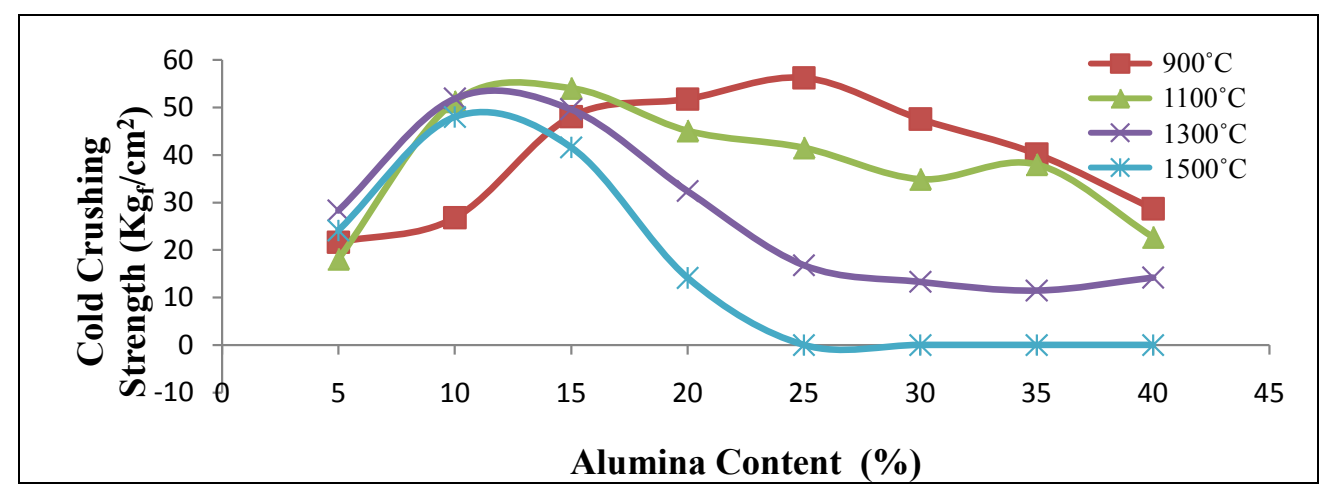

Figure 6. Variation of cold crushing strength with alumina contents of bricks fired at different temperatures.

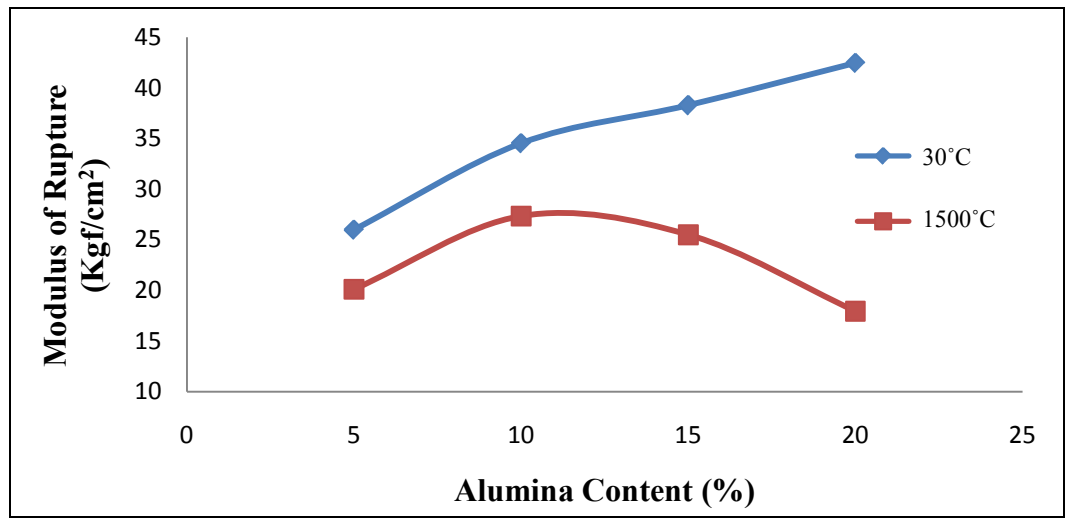

Figure 7. Variation of modulus of rupture with alumina contents at room temperature $\left(30^{\circ} \mathrm{C}\right)$ and $1500^{\circ} \mathrm{C}$.

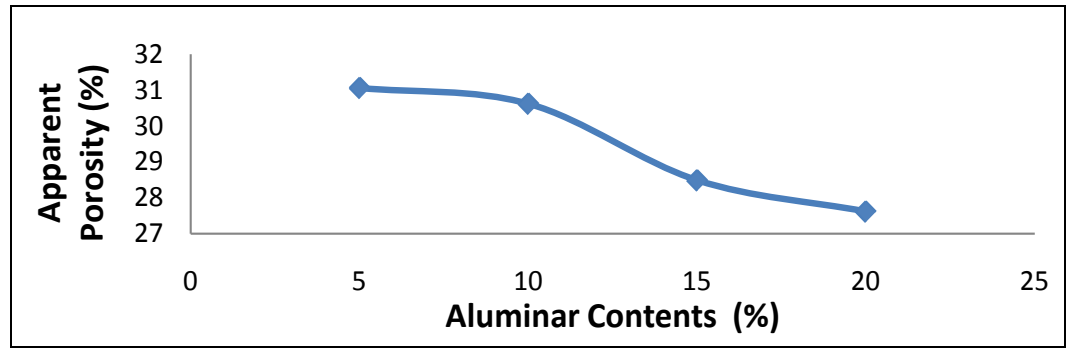

Figure 8. Variation of apparent porosities of bricks (without sawdust) with alumina.

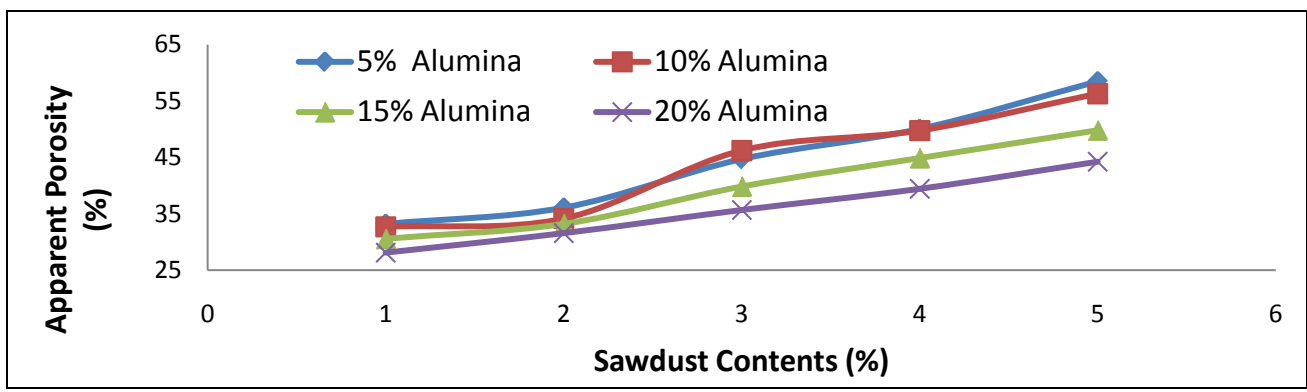

Figure 9. Variation of apparent porosities with sawdust.

content. The reduction is attributable to the increased binding effect of alumina in the samples, which binds the grains together, thereby reducing the interparticle distances and hence the reduction in the porosity. 
The results obtained show that $3 \%-5 \%$ sawdust exhibited the desired expectations; $\geq 45 \%$ porosity [6]. High strength, however, is incompatible with high porosity because the larger and more numerous the pores, the thinner the enclosing wall of solid material and the lower the strength [11]. Sample with $10 \%$ alumina and 3\% sawdust was therefore chosen as the most promising of the samples because it possesses apparent porosity of $46.22 \%$.

\section{Conclusions}

This research work has shown that the performance of an insulating firebrick at elevated temperatures is dependent, to a large extent, on the types and quantities of minerals contained therein.

Hydrometallurgical purification of clay enhanced the refractoriness of the insulating firebrick by reducing the quantities of the undesired (fusible quartz or microcline) and increasing the quantities of the desired (kaolinites and muscovites/illites) constituents of the brick.

The brick with $10 \%$ alumina cement and 3\% sawdust exhibited the most promising performance because it demonstrated a very close compliance with the standards in all the refractory properties tested.

\section{References}

[1] Wikipedia, the Free Encyclopedia (2014)

[2] Borode, J.O. and Olasupo, O.A. (2009) Development of Insulating Refractory Ramming Mass from Some Nigerian Refractory Raw Materials. Journal of Materials \& Materials characterization \& Engineering, 8, 667-678.

[3] Folorunso, D.O., Olubambi, P. and Borode, J.O. (2014) Characterization and Qualitative Analysis of Some Nigerian Clay Deposits for Refractory Applications. IOSR Journal of Applied Chemistry, 7, 40-47.

[4] Folorunso, D.O. (2014) Comparative Study of the Responses of Three Clay Deposits to Defferation by an Organic Acid. IOSR Journal of Mechanical and Civil Engineering, 11, 82-89.

[5] ASTM C 201-86 (1986) Standard Test Method for Porosity and Thermal Conductivity of Refractories. American Society for Testing and Materials, Pittsburg.

[6] ASTM C 133-84 (1984) Standard Test Method for Cold Crushing Strength and Modulus of Rupture of Refractory Brick and Shapes. American Society for Testing and Materials, Pittsburg.

[7] ASTM D 1857 (1987) Fusibility of Coke and Ash. American Society for Testing and Materials, Pittsburg.

[8] Refractories, an Overview of Journal of Materials Science and Engineering Information. www.azom.com

[9] Hosseini, M.R., Pazouki, M., Ranjbar, M. and Habibian, M. (2007) Bioleaching of Iron from Highly Contaminated Kaolin Clay by Aspergillus niger. Applied Clay Science, 37, 251-257. http://dx.doi.org/10.1016/j.clay.2007.01.010

[10] Chester, J.H. (1983) Refractoriness: Production and Properties. The Metal Society, London, 492-510.

[11] Jonker, A., Maree, D.B.G. and Van Der Merwe, M.J. (1998) Guidelines for Ceramic Techniques. Technikon Pretoria, Pretoria. 